\title{
THE EFFECT OF THE UPRIGHT POSTURE UPON HEPATIC BLOOD FLOW IN NORMOTENSIVE AND HYPERTENSIVE SUBJECTS ${ }^{1}$
}

\author{
BY JAMES W. CULBERTSON,2 ROBERT W. WILKINS, FRANZ J. INGELFINGER, \\ AND STANLEY E. BRADLEY ${ }^{3}$ \\ (From the Robert Dawson Evans Memorial, Massachusetts Memorial Hospitals, and the De- \\ partment of Medicine, Boston University School of Medicine, Boston, Mass.)
}

(Submitted for publication, June 2, 1950; accepted, January 2, 1951)

\section{INTRODUCTION}

The upright posture imposes a strain upon the cardiovascular system, chiefly as a result of its hydrostatic effects in the lower half of the body which, if unopposed, tend to produce hypotension in the upper half. These hydrostatic effects normally are counteracted by autonomic vasomotor adjustments, particularly in the splanchnic region. For example, the upright posture in man usually causes a reduction of renal blood flow (2). However, as yet no direct evidence has been reported concerning its effects upon the largest remaining portion of the splanchnic circulation, namely that draining through the liver. The present communication reports measurements of "hepatic blood flow" obtained with the bromsulfalein (BSP) extraction method (3) in normotensive and hypertensive subjects studied in the supine, in the upright, and again in the supine position.

\section{METHODS}

The estimated hepatic blood flow (EHBF) was measured by the intravenous catheterization method of Bradley and associates (3). The continuous infusion of BSP. was most easily maintained at a constant rate in both the horizontal and upright positions by suspending the infusion flask from a pole attached to the tilt table at such an angle that the flask remained at the same distance above the level of the subclavian vein when the table was horizontal or tilted up at $75^{\circ}$.

The subjects were hospital patients selected for study either because they had essentially normal cardiovascular systems or had arterial hypertension without evidence of cardiac, renal or hepatic insufficiency. All were studied

1 Presented May 5, 1947 at the Thirty-Ninth Annual Meeting of the American Society for Clinical Investigation, Atlantic City, New Jersey (1).

2 Present address-University Hospitals, Iowa City, Iowa.

8 Present address-Columbia University, College of Physicians and Surgeons, New York, New York. in the basal state, at first supine, then tilted (passively) into the upright $\left(75^{\circ}\right)$ position for periods of 10 to 25 minutes (unless weakness and hypotension supervened), and finally, supine again. They were requested to remain as relaxed and motionless as possible throughout the test. Arterial pressure and pulse rate were measured either by the usual clinical methods or (in Cam, Aye and Dun) with a Hamilton manometer (4) at short intervals during each experiment.

Spot roentgenograms of the hepatic area were taken in each patient before, during, and after the upright tilt to demonstrate that the catheter remained properly placed in the same position near the center of the right lobe of the liver. To avoid possible errors due to mechanical and hydrostatic disturbances incident to changing the position of the subject, no result was computed on blood samples obtained within three minutes after a tilt, except for a few determinations made on blood samples that were taken immediately after a quick return to the horizontal position necessitated by faintness of the patient. As noted in Table I, such determinations have been related to the period just before rather than after this change of position because there appeared to be a time lag of one to two minutes before there was evidence of any acute change in hepatic blood flow as reflected in altered concentrations of BSP in the blood samples. After this time lag, however, considerable changes in serum BSP concentration could take place with great rapidity, especially when the subject had been tilted from the supine to the upright position. About four minutes after a tilt the trend of the BSP levels became more steady and the results after this time were accepted as more reliable measurements of an equilibrium state than those obtained earlier after a change in position. Furthermore, some subjects tolerated the upright position easily (top of Table IA and IB) and the results in them during upright tilting were regarded as more reliable than in the less stable subjects, some of whom fainted (bottom of Table IA and IB, and Figure 3)."

An effort was always made to draw the last pair of blood samples in each period as late as possible before a change in tilt table position. All estimates of rate of blood flow were calculated for the actual times of sampling and on the observed rather than the interpolated

4 Only those data obtained after four minutes in a given position, and without fainting, are included in the statistical analysis in Table II. 
J. W. CULBERTSON, R. W. WILKINS, F. J. INGELFINGER, AND S. E. BRADLEY

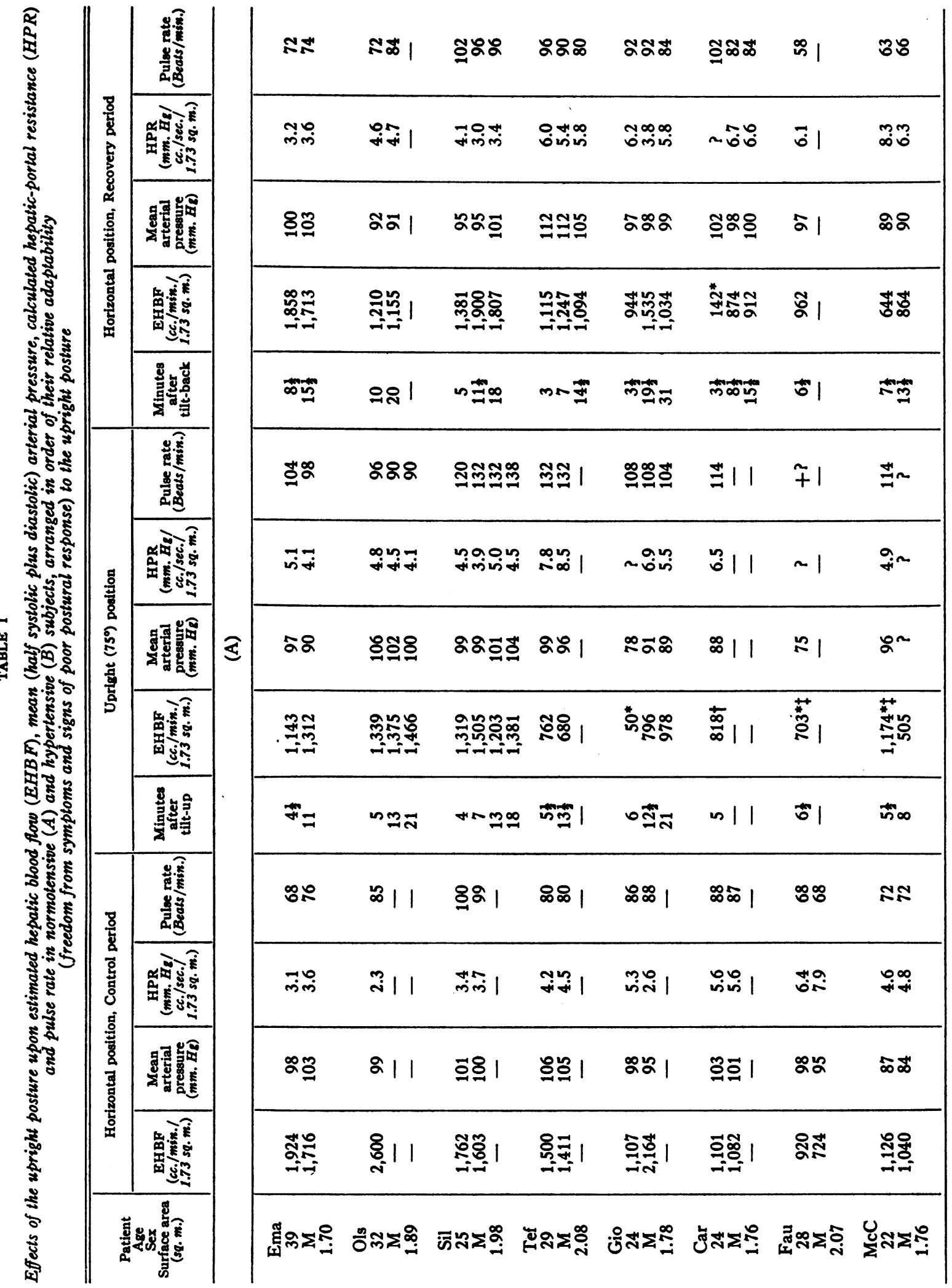


EFFECT OF UPRIGHT POSTURE ON HEPATIC BLOOD FLOW

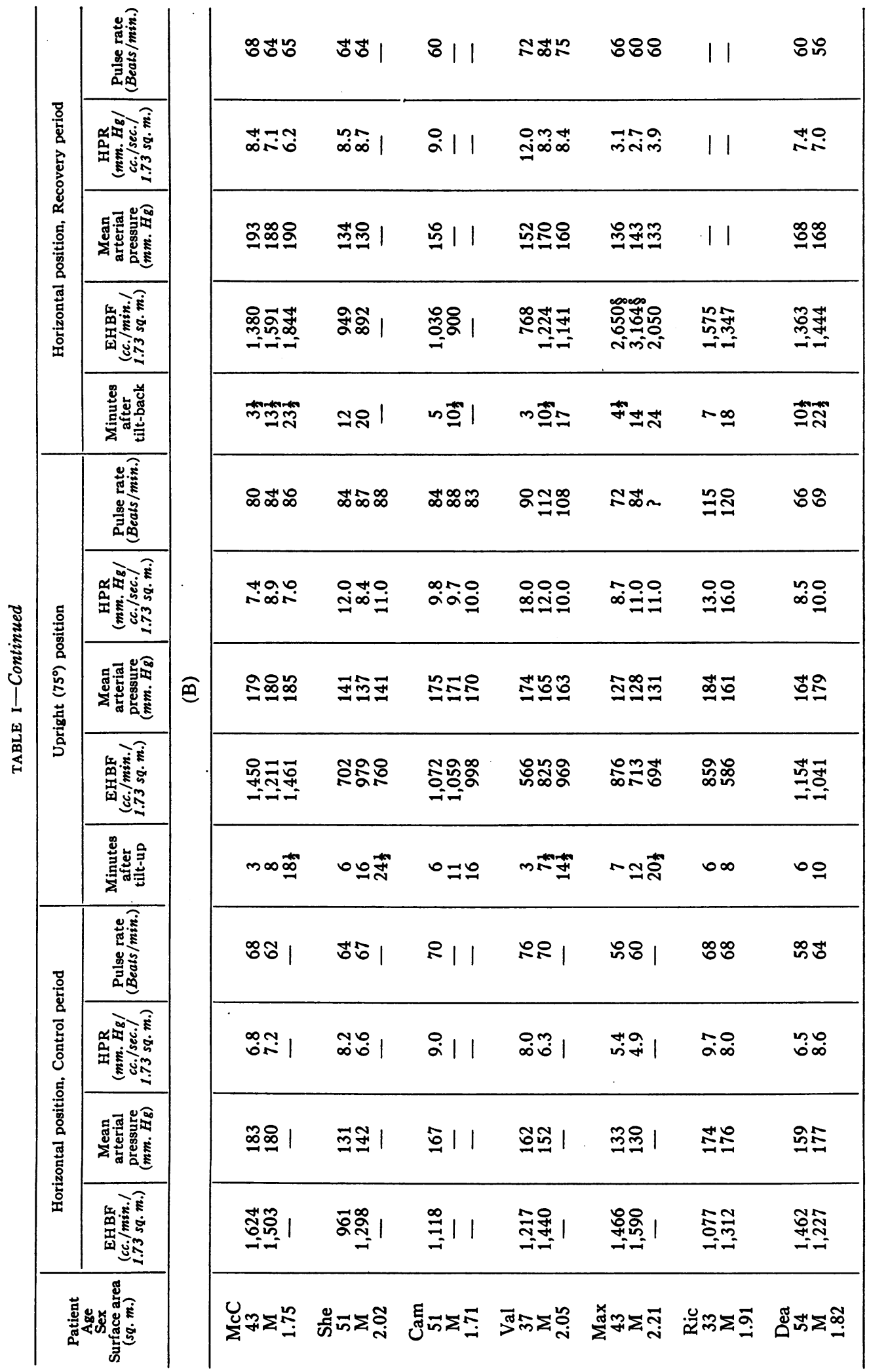


J. W. CULBERTSON, R. W. WILKINS, F. J. INGELFINGER, AND S. E. BRADLEY

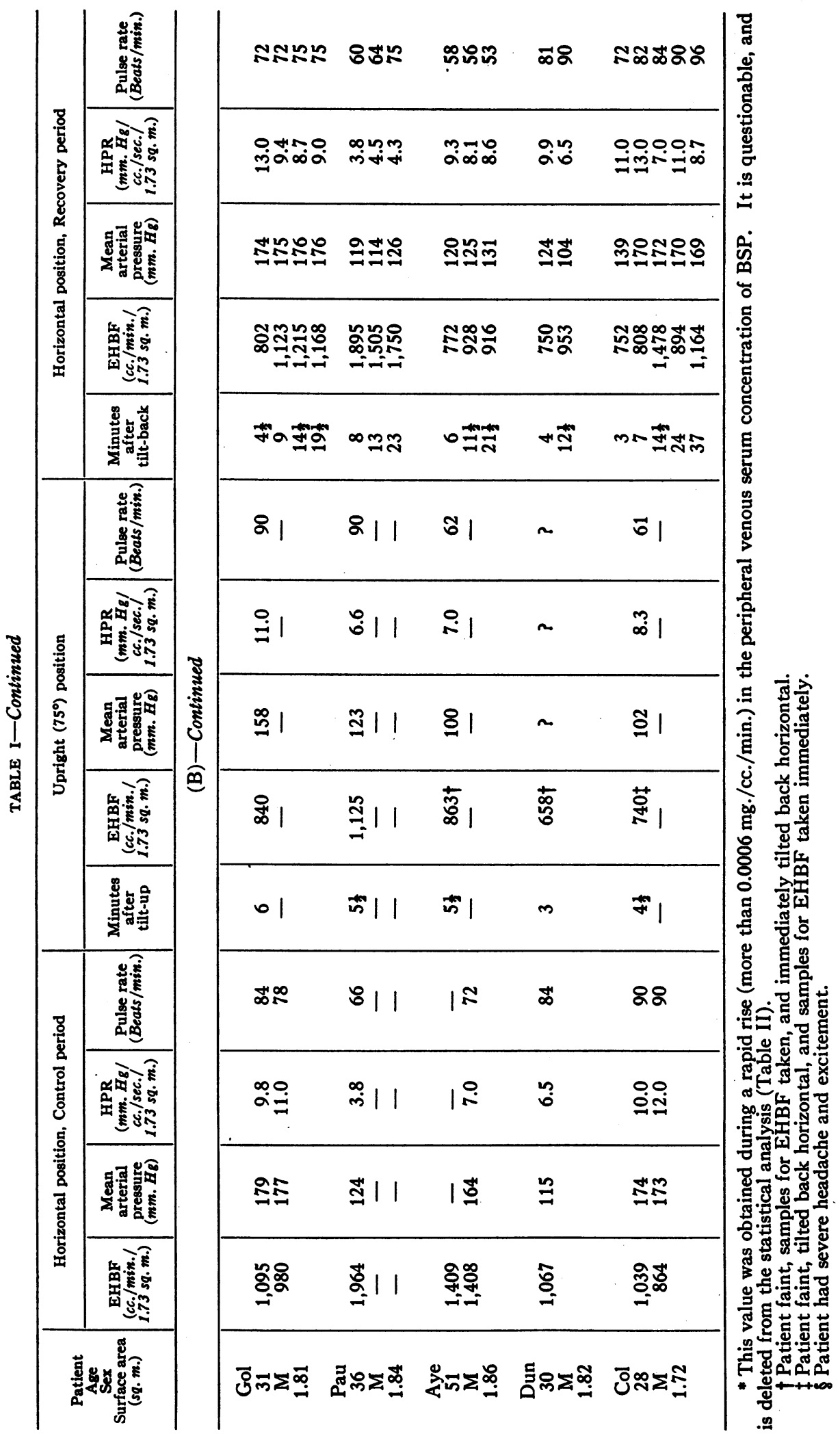


values for serum concentration of BSP. Rate of change $(\Delta \mathrm{P})$ in the peripheral venous or (in Cam, Aye and Dun) arterial concentration of BSP was taken as the calculated average for the preceding period in each instance. This value never exceeded $0.0006 \mathrm{mg} . / \mathrm{cc} . / \mathrm{min}$., except in four instances when the subject had been hypotensive ${ }^{5}$ (Table I). Blood volumes were calculated by the method of Gibson and Evans (5). All estimates of hepatic blood flow were corrected for standard surface area (1.73 sq.m.). Hepatic portal resistance (HPR) was calculated simply by dividing the "mean" (one-half systolic plus diastolic) arterial pressure by the EHBF per second.

A cold pressor test (6)-immersion of one hand in ice water for one minute-was applied to six (four normotensive and two hypertensive) subjects in the horizontal position after a period of recovery from the effects of the upright position. This was abandoned later because it was found to produce only equivocal effects upon EHBF.

\section{RESULTS}

A detailed presentation of data is given in Table I and a statistical summary in Table II. In both normotensive subjects (Table IA, Figure 1) and hypertensive patients (Table IB, Figure 2) the $\mathrm{EHBF}$ decreased following the tilt from the horizontal to the upright position. The decreases in

5 These data were omitted from the statistical analysis in Table II.

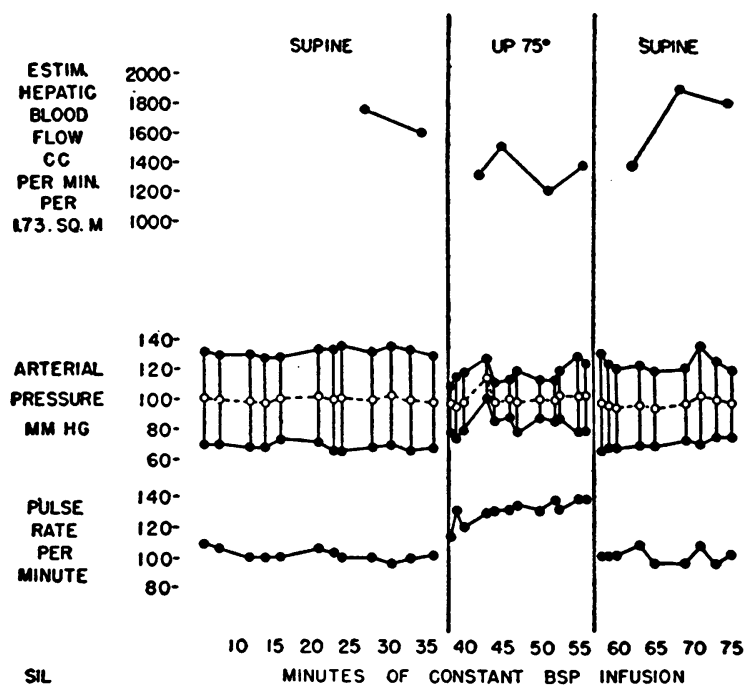

Fig. 1. Chart of EhBF, Arterial Pressure and Pulse Rate in a Normotensive Subject (Sil), in the Horizontal, Upright, aNd Again in the Horizontal Position

"Mean" arterial pressure (half systolic plus diastolic) is indicated by the open circles and interrupted line. At the first vertical line, the subject was tilted upright $\left(75^{\circ}\right)$ and at the second, horizontal again.

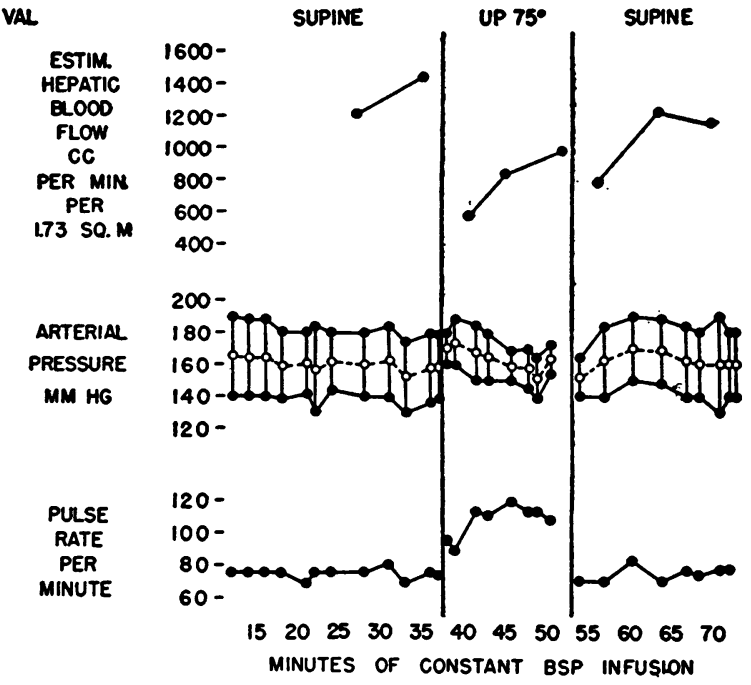

Fig. 2. Chart of EhbF, Arterial Pressure and Pulse Rate in a Hypertensive Patient (VaL)

Other notations as in Fig. 1.

EHBF were usually not associated with proportionate changes in mean arterial pressure, so that calculated hepatic-portal resistance (HPR) increased. Comparing only equilibrium values (Table II) the EHBF (cc./min.) decreased on the average from 1,713 to 1,070 in the normotensive group, from 1,357 to 960 in the hypertensive group, and from 1,499 to 1,004 in the combined groups. During the upright period, the average arterial pressure did not change, so that the HPR increased from 3.8 to 5.5 in the normotensive group, from 7.3 to 10.1 in the hypertensive group, and from 6.0 to 8.3 in the combined groups. These changes were significant statistically.

The changes in EHBF and HPR were not directly related to increases in pulse rate or to other signs and symptoms of poor circulatory adaptation to the upright posture (Table I). However, there was in general a correlation between the tendency of a subject to collapse and to have a low EHBF in the upright position. Thus, of the six subjects who fainted, four had an EHBF below 750 $\mathrm{cc}$./min. during the upright period and another had it just after being tilted back horizontal. Although six of the ten subjects who had an upright EHBF below $750 \mathrm{cc} . / \mathrm{min}$. did not faint, three (Gio, She, Val) of them had the low flow only during the first six minutes after being tilted up, and on further standing had an EHBF above $750 \mathrm{cc} . / \mathrm{min}$. 


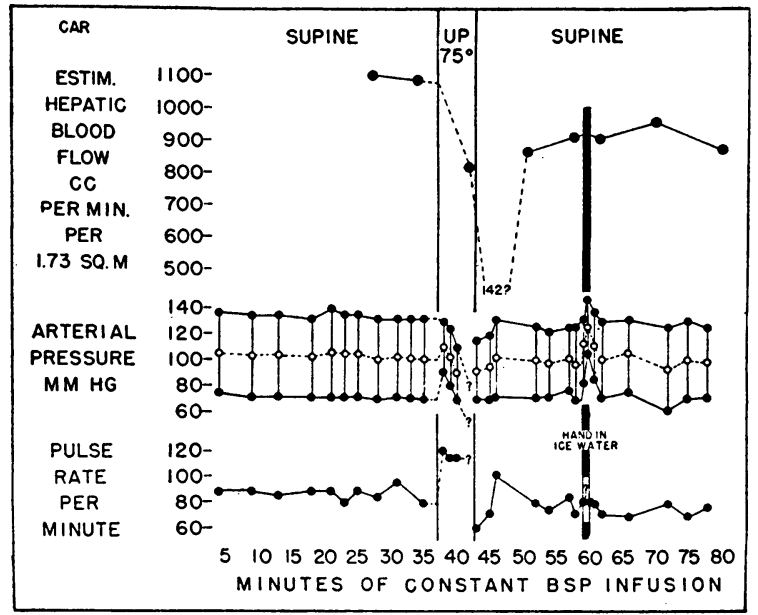

Fig. 3. Chart of EHBF, Arterial Pressure and

Pulse Rate in a Normotensive Patient (Car)

At the heavy vertical line the left hand was immersed in ice water for one minute. Other notations as in Fig. 1.

Upon returning the subjects from the upright to the horizontal position the EHBF and HPR usually returned toward, to, or even beyond the control horizontal levels after varying periods of time. In some subjects the returns were prompt, in others they were delayed or incomplete, or occurred only after an initial overshoot beyond the previous horizontal values. In one hypertensive individual ( $\mathrm{Max}$ ) the post-tilt increases of $\mathrm{EHBF}$ and decreases of HPR were extreme and associated with a marked anxiety reaction that began with a severe headache.

Upon tilting the subjects back to the horizontal position the average values (Table II) changed as follows: $\mathrm{EHBF}$ rose from 1,070 to 1,312 in the normotensive group, from 960 to 1,417 in the hypertensive group, and from 1,004 to 1,372 in the combined groups, while the HPR decreased from 5.5 to 4.9 , from 10.1 to 7.2 , and from 8.3 to 6.2 , respectively. Since the measurements during recovery showed greater variability than before tilting, the changes during this period, while significant for the combined and hypertensive groups, were not for the normotensive group considered separately.

Except in one patient (Sil), immersion of a

TABLE II

Mean values* of estimated hepatic blood flow $(E H B F)$, arterial pressure and hepatic portal resistance (HPR) in relation to posture, with a statistical analysis of the significance of the differences $\dagger$

\begin{tabular}{|c|c|c|c|c|c|c|c|c|c|}
\hline & \multicolumn{3}{|c|}{$\underset{(c c . / m i n . / 1.73 \text { sq. m. })}{\text { EHBF }}$} & \multicolumn{3}{|c|}{$\begin{array}{c}\text { Mean§ arterial pressure } \\
(m m . H g)\end{array}$} & \multicolumn{3}{|c|}{$\begin{array}{c}\text { HPR } \\
(\mathrm{mm} . \mathrm{Hg} / \mathrm{cc} . / \mathrm{sec} . / 1.73 \mathrm{sq} . \mathrm{m} .)\end{array}$} \\
\hline & $\begin{array}{l}\text { Horizontal } \\
\text { (Control) }\end{array}$ & Upright & $\mid \begin{array}{l}\text { Horizontal } \\
\text { (Recovery) }\end{array}$ & $\begin{array}{l}\text { Horizontal } \\
\text { (Control) }\end{array}$ & Upright & $\begin{array}{l}\text { Horizontal } \\
\text { (Recovery) }\end{array}$ & $\underset{\text { (Control) }}{\text { Horizontal }}$ & Upright & $\begin{array}{l}\text { Horizontal } \\
\text { (Recovery) }\end{array}$ \\
\hline $\begin{array}{l}\text { Normotensives }(\mathrm{n}=6) \\
\text { Mean } \\
\text { Standard Error of Mean } \\
\text { Mean Difference } \\
\text { Significance of Difference (P) }\end{array}$ & $\begin{array}{c}1,713 \\
65 \\
- \\
-\end{array}$ & $\begin{array}{r}1,070 \\
37 \\
-642 \\
<0.01\end{array}$ & $\begin{array}{r}1,312 \\
155 \\
+242 \\
0.12\end{array}$ & $\begin{array}{r}98 \\
3 \\
- \\
-\end{array}$ & $\begin{array}{r}97 \\
2 \\
-1 \\
0.75\end{array}$ & $\begin{array}{r}98 \\
3 \\
+1 \\
0.81\end{array}$ & $\begin{array}{l}3.8 \\
0.1 \\
- \\
-\end{array}$ & $\begin{array}{r}5.5 \\
0.6 \\
+1.7 \\
<0.03\end{array}$ & $\begin{array}{c}4.9 \\
0.6 \\
-0.6 \\
0.42\end{array}$ \\
\hline $\begin{array}{l}\text { Hypertensives }(\mathrm{n}=9) \\
\text { Mean } \\
\text { Standard Error of Mean } \\
\text { Mean Difference } \\
\text { Significance of Difference (P) }\end{array}$ & $\begin{array}{r}1,357 \\
97 \\
- \\
-\end{array}$ & $\begin{array}{r}960 \\
68 \\
-397 \\
<0.01\end{array}$ & $\begin{array}{r}1,417 \\
172 \\
+428 \\
<0.05\end{array}$ & $\begin{array}{r}158 \\
7 \\
- \\
-\end{array}$ & $\begin{array}{r}157 \\
7 \\
-1 \\
0.78\end{array}$ & $\begin{array}{r}155 \\
8 \\
0 \\
0.97\end{array}$ & $\begin{array}{l}7.3 \\
0.6 \\
- \\
-\end{array}$ & $\begin{array}{c}10.1 \\
0.7 \\
+2.8 \\
<0.01\end{array}$ & $\begin{aligned} 7.2 \\
0.7 \\
-2.4 \\
<0.01\end{aligned}$ \\
\hline $\begin{array}{l}\text { Combined Groups }(\mathrm{n}=15) \\
\text { Mean } \\
\text { Standard Error of Mean } \\
\text { Mean Difference } \\
\text { Significance of Difference (P) }\end{array}$ & $\begin{array}{r}1,499 \\
107 \\
-\end{array}$ & $\begin{array}{r}1,004 \\
61 \\
-495 \\
<0.01\end{array}$ & $\begin{array}{r}1,372 \\
116 \\
+348 \\
<0.01\end{array}$ & $\begin{array}{r}134 \\
9 \\
-\end{array}$ & $\begin{array}{r}133 \\
9 \\
-1 \\
0.77\end{array}$ & $\begin{array}{r}131 \\
9 \\
0 \\
0.87\end{array}$ & $\begin{array}{l}6.0 \\
0.6 \\
-\end{array}$ & $\begin{aligned} & 8.3 \\
& 0.8 \\
+ & 2.3 \\
< & 0.01\end{aligned}$ & $\begin{array}{l}6.2 \\
0.6 \\
-1.6 \\
<0.01\end{array}$ \\
\hline
\end{tabular}

* These data represent the group means calculated from the average values of EHBF, arterial pressure and HPR for each patient, shown in detail in Table I. Non-equilibrium observations $(i . e$., those prior to four minutes af ter a change in posture, as well as those associated with a faint) were deleted from the calculations.

$\dagger$ The significance of the differences was calculated by Fisher's method for the significance of unique samples (12). $P$ represents the probability that a difference may be due to chance. Values of 0.05 or less (in bold type) denote a "significant" difference, and 0.01 or less a "highly significant" one.

$¥$ The differences refer to the change from the immediately preceding posture. Slight discrepancies between the mean changes from upright back to horizontal as compared to the mean values in these positions are due to the fact that observations were made on one hypertensive patient (Ric) during the control and upright periods, but not during recovery.

$\S$ Average of the systolic and diastolic pressures. 
hand in ice water for one minute caused slight or negligible effects upon EHBF, although it usually caused a temporary elevation of arterial pressure (Figure 3) and HPR. It was felt that this stimulus, despite its severity, was too brief in duration to produce regular effects upon EHBF; consequently, it was abandoned.

\section{DISCUSSION}

The results reported above confirm the impression gained from indirect evidence that active vasoconstriction occurs in splanchnic organs in addition to the kidneys when human subjects are tilted into the upright position. The decreases in $\mathrm{EHBF}$ found in the upright position can not be explained by changes in arteriovenous pressure gradient because the arterial pressure did not decrease proportionately and the atrial venous pressure is known not to increase in this position (7). Neither can the decreases in EHBF be attributed to other passive hydrostatic effects such as changes in blood volume (8) or intra-abdominal pressure (9). That the decreases in EHBF in the upright position are probably due to active vasoconstriction of sympathetic nervous origin has been indicated by repeating the studies of EHBF in some of the same subjects after splanchnicectomy (10).

No consistent differences in EHBF were found between the small group of hypertensive patients here reported and a larger group of normotensive subjects (11). The data indicate that the splanchnic circulation is not increased in hypertensive patients, but that calculated HPR is increased, reflecting the generalized vascular hypertonus usually regarded as characteristic of the disease. More evidence is being accumulated concerning these points by comparing the EHBF and HPR in the resting horizontal position in larger groups of hypertensive and normotensive subjects and will form the subject of a later report (11).

\section{SUMMARY}

Hepatic blood flow, as estimated by the bromsulfalein extraction method, decreased in eight normotensive and 12 hypertensive subjects after passive tilting into the upright $\left(75^{\circ}\right)$ position.
It failed to change regularly in six subjects after immersion of a hand in ice water for one minute.

\section{ACKNOWLEDGMENTS}

The authors gratefully acknowledge the statistical analysis by Dr. Meyer H. Halperin, the technical assistance of Miss Adele Rymut and Miss Doris Bullard, and the photographic work of Miss Jane Holbrook.

\section{REFERENCES}

1. Culbertson, J. W., Wilkins, R. W., Ingelfinger, F. J., and Bradley, S. E., The effect of the upright posture upon hepatic blood flow in normal and hypertensive human subjects. J. Clin. Invest., 1947, 26, 1178.

2. Smith, H. W., Studies in the Physiology of the Kidney. Porter Lectures, Series IX. Univ. Extension Division, Univ. of Kansas, Lawrence, Kansas, 1939.

3. Bradley, S. E., Ingelfinger, F. J., Bradley, G. P., and Curry, J. J., The estimation of hepatic blood flow in man. J. Clin. Invest., 1945, 24, 890.

4. Hamilton, W. F., Brewer, G., and Brotman, I., Pressure pulse contours in the intact animal. I. Analytic description of a new high-frequency hypodermic manometer with illustrative curves of simultaneous arterial and intracardiac pressure. Am. J. Physiol., 1934, 107, 427.

5. Gibson, J. G., II, and Evans, W. A., Jr., Clinical studies of the blood volume. II. The relation of plasma and total blood volume to venous pressure, blood velocity rate, physical measurements, age and sex in 90 normal humans. J. Clin. Invest., 1937, 16, 317.

6. Hines, E. A., and Brown, G. E., A standard test for measuring the variability of blood pressure: its significance as an index of the pre-hypertensive state. Ann. Int. Med., 1933, 7, 209.

7. Wilkins, R. W., Bradley, S. E., and Friedland, C. K., The acute circulatory effects of the head-down position (Negative $G$ ) in normal man, with a note on some measures designed to relieve cranial congestion in this position. J. Clin. Invest., 1950, 29, 940.

8. Freis, E. D., Culberston, J. W., and Wilkins, R. W., Unpublished observations.

9. Wilkins, R. W., Bradley, S. E., and Ingelfinger, F. J., Unpublished observations.

10. Wilkins, R. W., Culbertson, J. W., and Ingelfinger, F. J., The effect of splanchnic sympathectomy in hypertensive patients upon estimated hepatic blood flow in the upright as contrasted with the horizontal position. J. Clin. Invest., 1951, 30, 312.

11. Wilkins, R. W., and Culbertson, J. W., The hepatic blood flow in resting hypertensive patients before and after splanchnicectomy. In preparation.

12. Fisher, R. W., Statistical Methods for Research Workers. Oliver \& Boyd, London, 1941, Ed. 8. 